\title{
Theoretical and Experimental Verification of Dynamic Behaviour of a Guided Spline Arbor Circular Saw
}

\author{
Ahmad Mohammadpanah ${ }^{1}$ and Stanley G. Hutton ${ }^{2}$ \\ ${ }^{1}$ FPInnovations, 2665 East Mall, Vancouver, BC, Canada \\ ${ }^{2}$ Department of Mechanical Engineering, The University of British Columbia, Vancouver, BC, Canada V6T $1 Z 4$ \\ Correspondence should be addressed to Ahmad Mohammadpanah; ahmadpa20@gmail.com
}

Received 16 April 2017; Revised 11 August 2017; Accepted 28 September 2017; Published 7 November 2017

Academic Editor: Ivo Caliò

Copyright (C) 2017 Ahmad Mohammadpanah and Stanley G. Hutton. This is an open access article distributed under the Creative Commons Attribution License, which permits unrestricted use, distribution, and reproduction in any medium, provided the original work is properly cited.

\begin{abstract}
An analysis of the dynamic and stability characteristics of a guided wood cutting spline arbor circular saw is presented. A multibody dynamic model is developed to consider the idling and cutting characteristics. The model considers the interaction between the blade, the arbor, and the guide pads. The model is capable of analyzing in-plane and out-of-plane edge forces which enables simulation of the cutting performance of the saw. In order to verify the computer model, an experimental test of a guided spline saw during idling run-up is presented. The frequencies and amplitudes of the blade vibrations are documented and plotted. Cutting tests are also conducted and the cutting forces are estimated. The results of a simulation of the idling response of the blade by the computer model and the experimental results are in a good agreement. Factors that significantly affect the characteristics of guided spline saws during cutting are discussed. The computer model is shown to be capable of predicting stable cutting operations of a guided spline saw.
\end{abstract}

\section{Introduction}

Traditionally for primary breakdown of logs in the wood product industry, both "clamped saws" and "guided spline arbor saws" have been used. In recent years guided spline arbor saws have been universally used in North America and clamped saws are no longer common in the primary wood manufacturing. In a clamped saw, the saw is clamped by a central collar and rigidly is fixed to the arbor. In spline guided saws, the saw fits loosely on a spline arbor. The arbor provides the driving force to the blade with the matching inner spline (similar to the gears motion). The blade is constrained laterally by guide pads (Figure 1). There is usually a gap of the order of $0.1 \mathrm{~mm}$ between the blade and guide pads. This gap is fed with a lubricant which is usually a combination of oil, water, and pressured air.

At high speeds blade vibrational instabilities can exist which lead to poor cutting accuracy. The number of variables that affect cutting performance at high speeds is large and their interaction is complex. Such factors are blade speed, blade geometry, tooth geometry, blade flatness, temperature distribution in the blade, depth of cut, wood characteristics, guide size, and location [1]. Currently mathematical modeling of the cutting behavior of guided circular saws involves a calculation of the variation of saw natural frequencies with rotation speed and a determination of the lowest critical speed of the saw [1-9]. The response of the saw to assumed applied external forces can also be calculated [1-5]. Consideration of parameters such as the interaction forces between the blade and the spline arbor, friction between parts, and clearance between the blade and the guide has not been considered in previous works. Interaction between the arbor and the spline blade adds considerably to the complexity of the saw blade behavior. Moreover, the cutting characteristics of guided saws are extremely complicated, and the forces applied to the blade tooth during cutting are not well defined.

In most of researches a disk is used as an idealized model of a saw by ignoring the teeth. Since the effect of teeth at low frequency vibrations (below $200 \mathrm{~Hz}$ ) is negligible, a flat thin disk is an acceptable approximation of dynamic behaviour of saw [2]. 


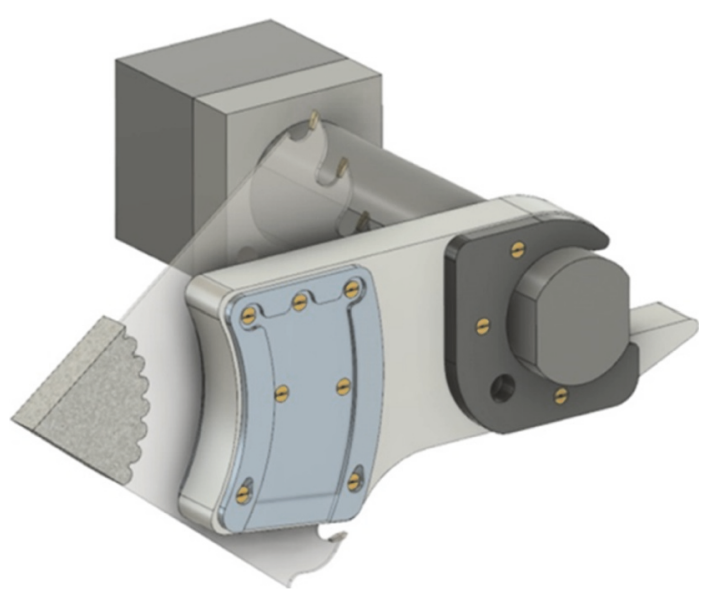

(a)

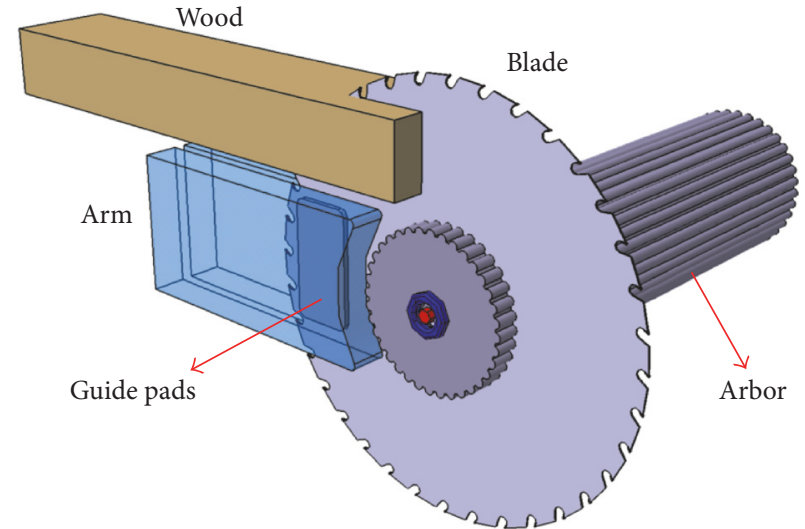

(b)

FIgURE 1: A guided spline saw, practical setup (a), and schematic (b).

A large portion of the existing literature is concerned with the idling and forced vibration characteristics of clamped circular disks. The number of studies relating to guided spline disks is limited. Khorasany et al. [6] investigated the idling dynamic characteristics of guided spline circular saws experimentally and numerically. Khorasany and Hutton [7] investigated analytically the stability characteristics of guided spinning disks having rigid body translational degrees of freedom. Chen and Bogy [8] investigated the effect of rigid body tilting on the natural frequencies and stability of rotating disks, subjected to a rotating load system. Chen and Wong [9] studied analytically the vibration and stability of a spinning disk with axial spindle displacement in contact with a number of fixed springs. Schajer and Wang [10] identified the workpiece interaction with the saw body as an important factor influencing guided circular saw cutting stability. Schajer [11], by using a geometrical model, explained the "hunting behaviour" of a guided spline saw, where the saw blade does not remain perpendicular to the drive shaft but always shifts to one side or the other. Recently, Mohammadpanah and Hutton [1-5] conducted comprehensive analytical and experimental tests and showed the maximum stable cutting operation of spline guided saws. They proved that a guided spline disk, subjected to edge loads, is stable up to its lowest flutter speed which occurs after the second critical speeds [5]. It is shown analytically and experimentally that the maximum stable operating speed of a guided spline saw for cutting wood is defined as the initiation of flutter [4].

In the present paper the dynamic behaviour of a guided spline saw subjected to all components of cutting forces (radial, tangential, and lateral components for each tooth in the cut) and considering the interaction forces between the blade and spline arbor are investigated. A multibody dynamic model of the system that includes geometrical details and physical properties of a guided spline saw is developed. The interaction forces between the blade and the spline arbor and geometrical details in the governing equations of motion are complex and have not previously been considered in the mathematical modeling of the problem. A finite element model of the guided saw is developed utilizing ANSYS [12] and MSC ADAMS [13]. This model assists in overcoming some of the limitations that have been encountered previously in modeling of guided spline saws. The model is capable of analyzing and simulating the cutting performance of the saw. The use of such model, even if it is not capable of representing all aspects of sawing behaviour exactly, at the very least, leads to a greater understanding of the fundamentals of the problem which in turn is likely to help in the development of improved technology. Comprehensive experimental idling and cutting tests are conducted to verify the computer model. Research results of FEM of guided circular saw may lead to better understanding of the vibration behaviour of system and more accurate prediction of critical and flutter instability speeds of the system, which can help in improving the design of an optimum circular saw.

\section{Multibody Dynamic Modeling of a Guided Spline Saw}

First the mode shapes and associated frequencies of the stationary saw blade are computed, using the finite element package (ANSYS). The element type used in FEM is plate element (2D planar) with combination of 3 or 4 nodes. In order to avoid very small element size, the teeth are not modeled. As mentioned above, the effect of teeth on the behaviour of saw at frequencies below $200 \mathrm{~Hz}$ is not significant [2] and a disk can be used as an idealized approximation of a saw blade. After building the FEM of the saw in ANSYS. The model is exported as a modal natural file and then it is imported to MSC ADAMS. The interaction between the modal natural file of the blade and the other components is modeled in MSC ADAMS.

The geometrical and physical properties of the guided saw used in the computer model are summarized in Table 1.

Figure 2(a) shows the schematic of the computer model of the system. Figure 2(b) shows the FEM of the disk (saw with no teeth). Figure 2(c) shows, as an example, the first 4 modes of the free disk. The bending natural mode shape 


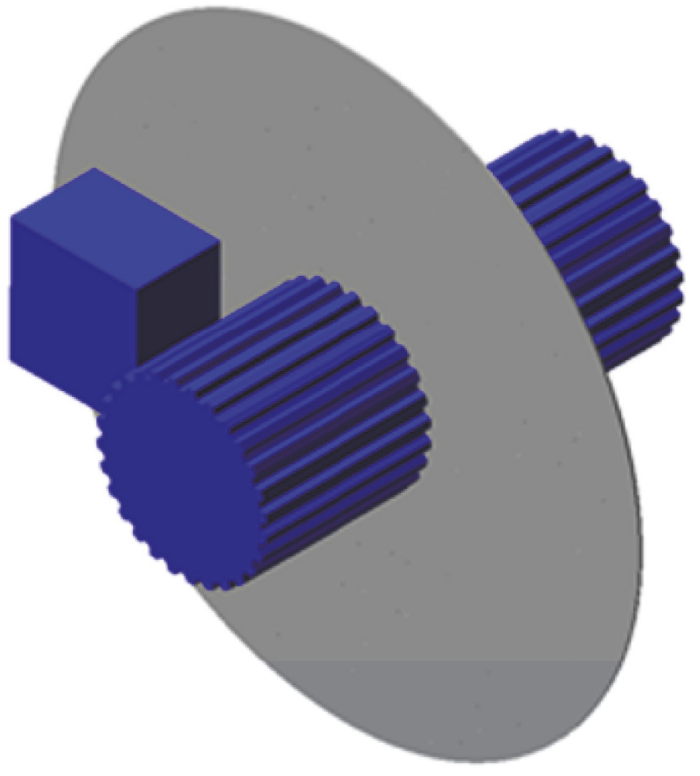

(a)
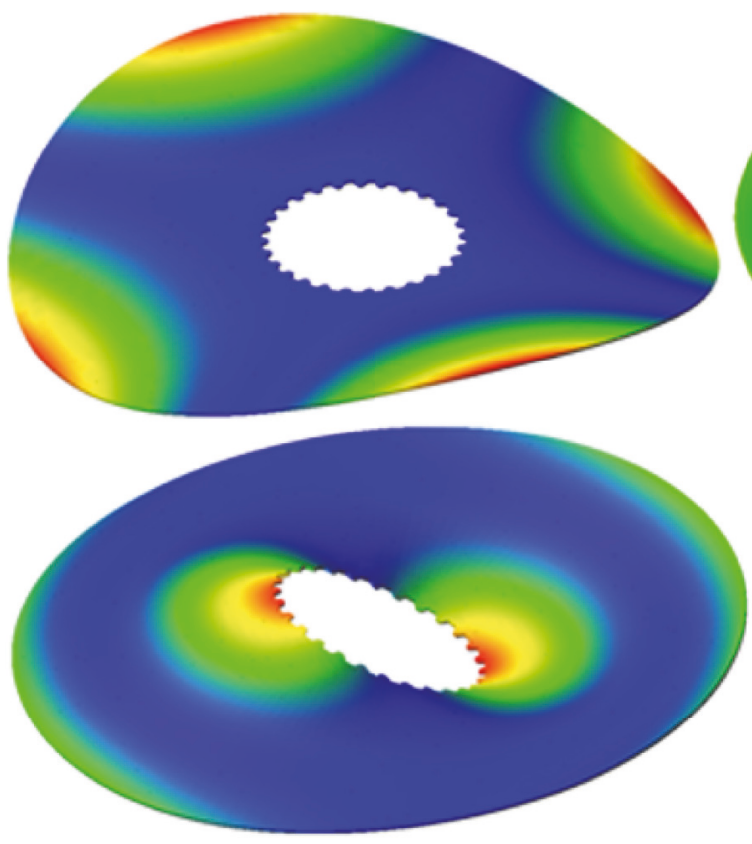

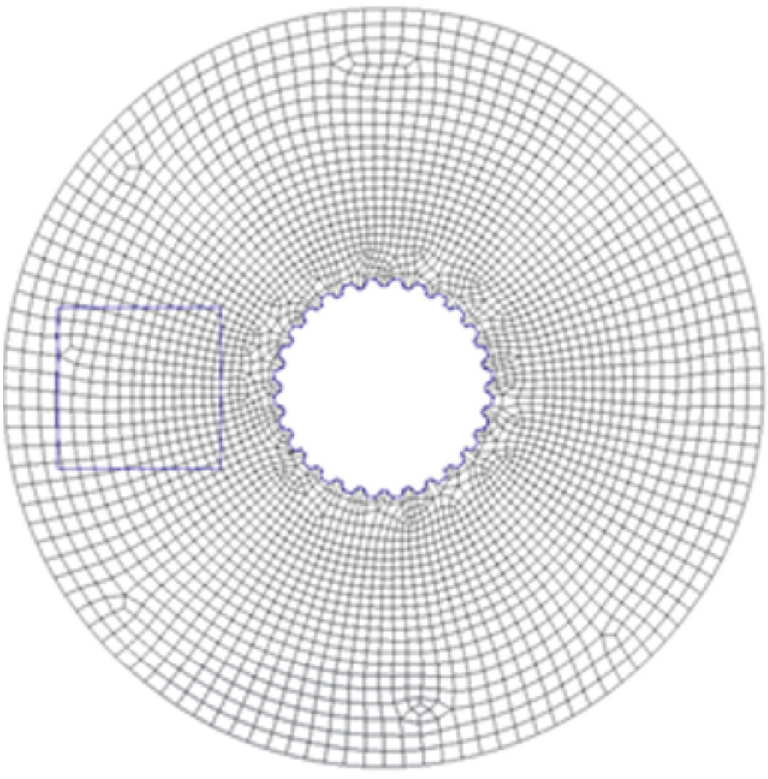

(b)
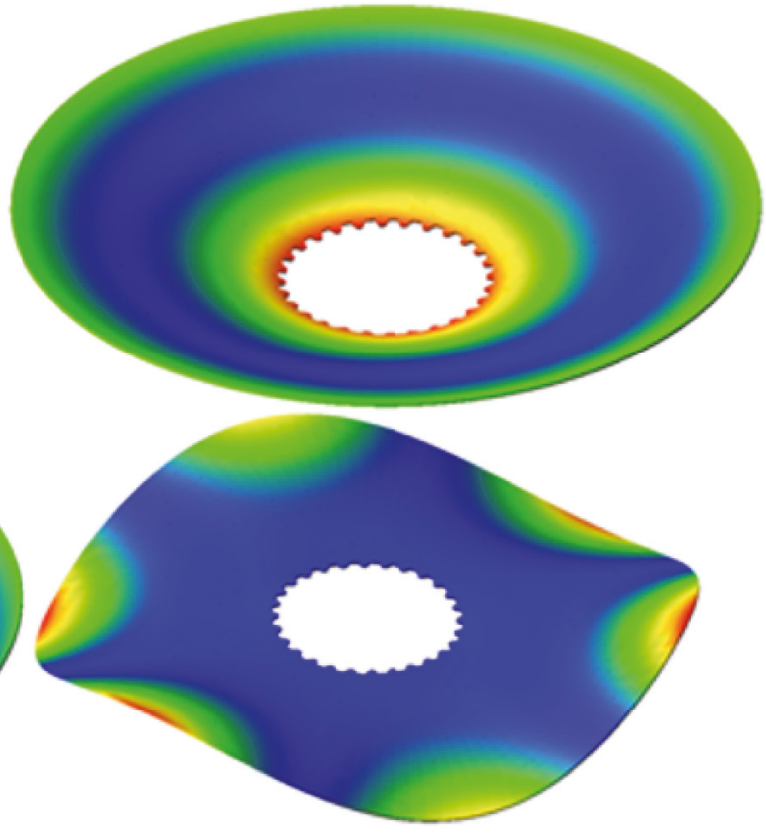

(c)

FIgURE 2: (a) Schematic of a multibody dynamics model of the guided saw, (b) FEM of the blade, and (c) the first 4 modes of a free blade: $(0,2),(0,0),(1,1)$, and $(0,3)$ modes with frequency of $27.7,46.6,69.1$, and $103.5 \mathrm{~Hz}$, respectively.

TABLE 1: Geometrical and physical properties of the guided saw.

\begin{tabular}{lcc}
\hline Number & Property & Value \\
\hline$(1)$ & Outer diameter $(\mathrm{m})$ & 0.710 \\
$(2)$ & Inner diameter $(\mathrm{m})$ & 0.200 \\
$(3)$ & Blade thickness $(\mathrm{m})$ & 0.0028 \\
$(4)$ & Number of teeth & 42 \\
$(5)$ & Guide pad size $(\mathrm{m} \times \mathrm{m})$ & $0.15 \times 0.15$ \\
$(6)$ & Module of elasticity $(\mathrm{pa})$ & $2.03 \times 10^{11}$ \\
$(7)$ & Poisson's ratio & 0.29 \\
\hline
\end{tabular}

of a disk is usually shown in a form of $(m, n)$ with $m$ representing the number of modal circles and $n$ being the number of nodal diameters. As shown in Figure 2(c), the first bending mode is a mode with zero nodal circles and two nodal diameters. The second mode which is in a shape of a dish is a mode with zero nodal circles and zero nodal diameters. The next two modes are also shown in this figure. Keep in mind that the rigid body translational and tilting modes (zero natural frequencies) are also considered in the model. Here, just the first 4 bending modes are displayed 


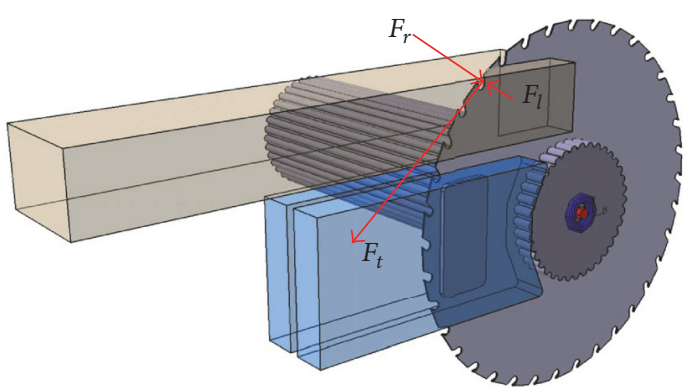

(a)

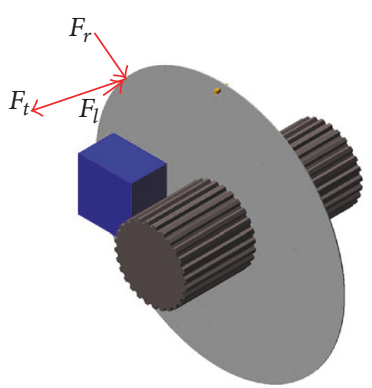

(b)

FIGURE 3: Schematic of the computer model with the components of cutting forces, $F_{r}, F_{t}$, and $F_{l}$ are radial, tangential, and lateral components of the force (b). The component of cutting forces on a teeth (a).

as an example. The modes with higher frequencies up to 3 nodal diameters and 6 nodal circles are considered in the model. All the geometrical details of the inner spline are considered in the FEM of the saw blade and the arbor. The clearance between the spline arbor and the matching spline of the disk is $0.25 \mathrm{~mm}$, and the clearance between the disk and the guides is $0.05 \mathrm{~mm}$. In practice this gap is filled with pressured water and oil. Since the gap is small $(0.05 \mathrm{~mm})$ using the linear spring for modeling the contact between the disk and the guides is an acceptable approximation [2]. The contact between the disk and the spline arbor is modeled using Heinrich Hertz contact modeling [14]. This contact is nonlinear and the parameters are calculated based on the geometrical and material properties of the blade and arbor. The boundary condition of the disk at the interface with the spline is considered to be free, unless the spline disk and the spline arbor are in contact. In other words, there is no clamping between the spline arbor and the inner radius of saw. Note that, due to the clearance between the inner spline of saw and the arbor, the center of the disk is no longer the center of rotation. In fact, the point or points of contact might change depending on gravity, centrifugal force, the deflection of the disk, and the external forces. At the points where the spline disk and spline arbor make contact, the nonlinear Hertz contact model is applied. The spline pattern on the inner radius of saw is matched with the spline arbor, and the contact between the arbor and saw provides the driving force for rotating of the saw. It is rational to think of the contact between the saw and the spline arbor to be similar to the contact of two gears, where at the point of contact between each gear the forces are modeled using the nonlinear Hertz model [14]. The model has the following form [14] and the value of $K$ and $C$ is estimated based on the material property of saw and arbor.

$$
F=K x^{3 / 2}+C \dot{x}^{3 / 2}
$$

In this computer models $K$ and $C$ are estimated as $2.2 \times$ $10^{5} \mathrm{~N} / \mathrm{m}$ and $0.15 \mathrm{~N} \cdot \mathrm{s} / \mathrm{m}$, respectively.

A separate subroutine code has been developed in MSC ADAMS to simulate the cutting performance of the system. The forces are applied at each tooth involved in a cut, in the form of pulsating conservative tangential, radial, and lateral forces. Figure 3 shows the schematic of the model with the components of the cutting forces. $F_{r}, F_{t}$, and $F_{l}$ are space fixed radial, tangential, and lateral components of the cutting force. Based on depth of cut and blade tooth pitch there are a defined number of teeth in the cut. The components of force are applied to each tooth in the cut. Experimental results are used for finding the components of cutting forces.

To determine the cutting forces, several cutting tests with a particular wood (in this research the wood specie was Douglas Fir) and a certain depth of cut and a constant feed speeds were conducted.

Estimating the cutting forces during cutting can be done by calculating the power consumption during cutting. Kazimierz and Ochrymiuk recently developed a model for predicting the power consumption during cutting with circular saws [15]. Kaczmarek et al. used a finite element model for predicting the natural frequencies of a circular saw [16].

In order to determine the tangential cutting force, the power consumption was measured during cutting, using an electrical power meter. The average of power consumption for 4 cutting tests results was used to determine the cutting forces as input for the computer model. Figures 4 and 5 show the power consumption during a cut for the experimental cutting tests at $1800 \mathrm{rpm}$ and $2800 \mathrm{rpm}$, respectively. The mean values of power consumption are summarized in Table 2.

The tangential force and feed force were estimated based on the measured power using the formula presented in [17]. The results are summarized in Table 3.

To measure the lateral cutting forces, a force transducer (Figure 6) was placed between the guide arms and the machine frame (Figure 7).

For the experimental cutting tests, 4 boards, with a $200 \mathrm{~mm}$ depth of cut (the wood specie was Douglas Fir), were used. It should be noted that since wood is not a homogeneous material and due to existence of knots in the wood, the cutting forces along the board are not constant. The cutting forces for the input in the computer model were approximated by computing the mean value of the experimental cutting forces results.

Figures 8 and 9 show the measured lateral force for cutting at $1800 \mathrm{rpm}$ and $2800 \mathrm{rpm}$. Note that these two saw speeds were chosen to be below the flutter speed to represent a stable 
TABLE 2: Mean value of power consumption during sutting.

\begin{tabular}{lcccccc}
\hline Number & $\begin{array}{c}\text { Rotation speed } \\
(\mathrm{rpm})\end{array}$ & $\begin{array}{c}\text { Power } \\
\text { consumption } \\
\text { Cut 1 (hp) }\end{array}$ & $\begin{array}{c}\text { Power } \\
\text { consumption } \\
\text { Cut 2 (hp) }\end{array}$ & $\begin{array}{c}\text { Power } \\
\text { consumption } \\
\text { Cut 3 (hp) }\end{array}$ & $\begin{array}{c}\text { Power } \\
\text { consumption } \\
\text { Cut 4 (hp) }\end{array}$ & $\begin{array}{c}\text { Average power } \\
\text { consumption } \\
(\mathrm{hp})\end{array}$ \\
\hline$(1)$ & 1800 & 57 & 62 & 58 & 55 & 58 \\
$(2)$ & 2800 & 81 & 80 & 80 & 78 & 80 \\
\hline
\end{tabular}

TABLE 3: Summarized cutting forces, based on experimental cutting tests.

\begin{tabular}{lcccccc}
\hline Number & $\begin{array}{c}\text { Depth of cut } \\
(\mathrm{mm})\end{array}$ & $\begin{array}{c}\text { Rotation Speed } \\
(\mathrm{rpm})\end{array}$ & Bite/tooth $(\mathrm{mm})$ & $\begin{array}{c}\text { Lateral } \\
\text { force/tooth }(\mathrm{N})\end{array}$ & $\begin{array}{c}\text { Tangential } \\
\text { force/tooth }(\mathrm{N})\end{array}$ & $\begin{array}{c}\text { Radial } \\
\text { force/tooth }(\mathrm{N})\end{array}$ \\
\hline Test 1 & 200 & 1800 & 0.75 & 3 & 1064 & 75 \\
Test 2 & 200 & 2800 & 0.75 & 4.5 & 1240 & 88 \\
\hline
\end{tabular}

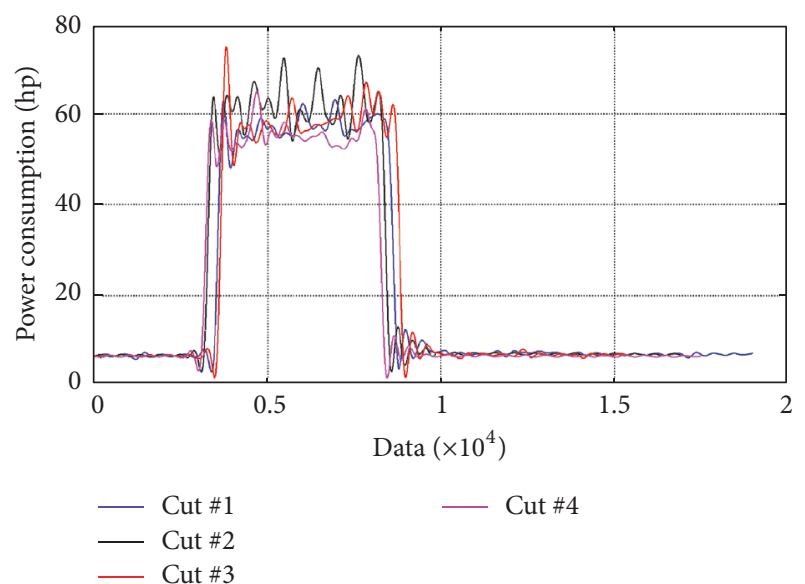

FIGURE 4: Measured power consumption during cutting, tests at $1800 \mathrm{rpm}$.

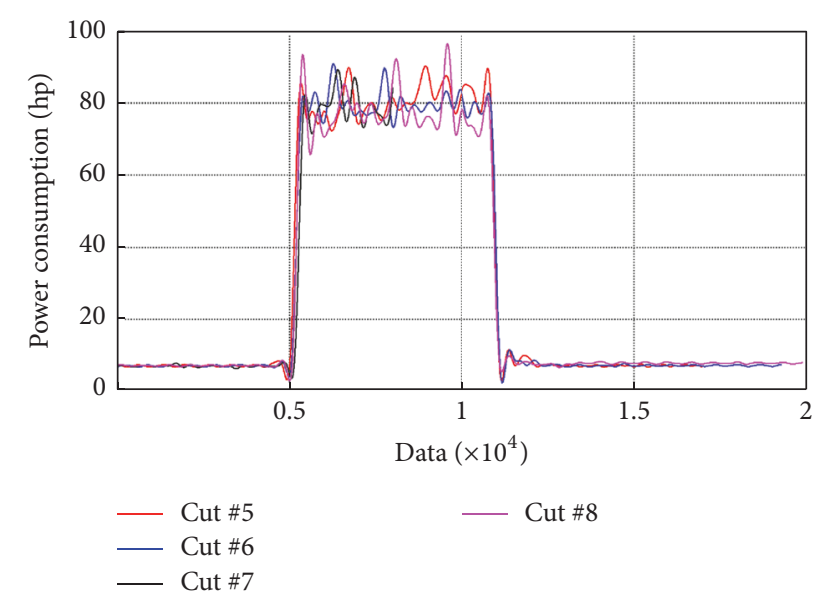

FIGURE 5: Measured power consumption during cutting, tests at $2800 \mathrm{rpm}$.

operation speed and one at super-flutter speed (more details will be provided in the next section). The mean value of the lateral force measured by the transducer during one cut was

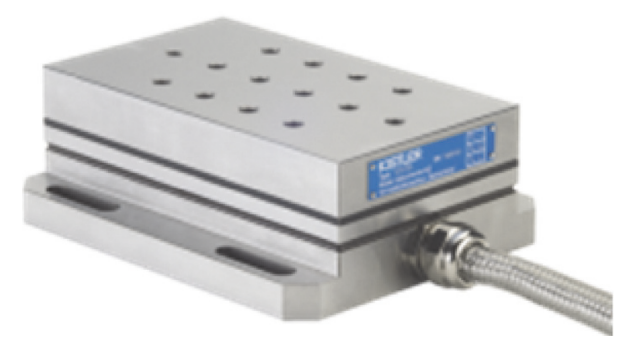

Figure 6: Force transducer (Kistler Dynamometer Type 9257B).

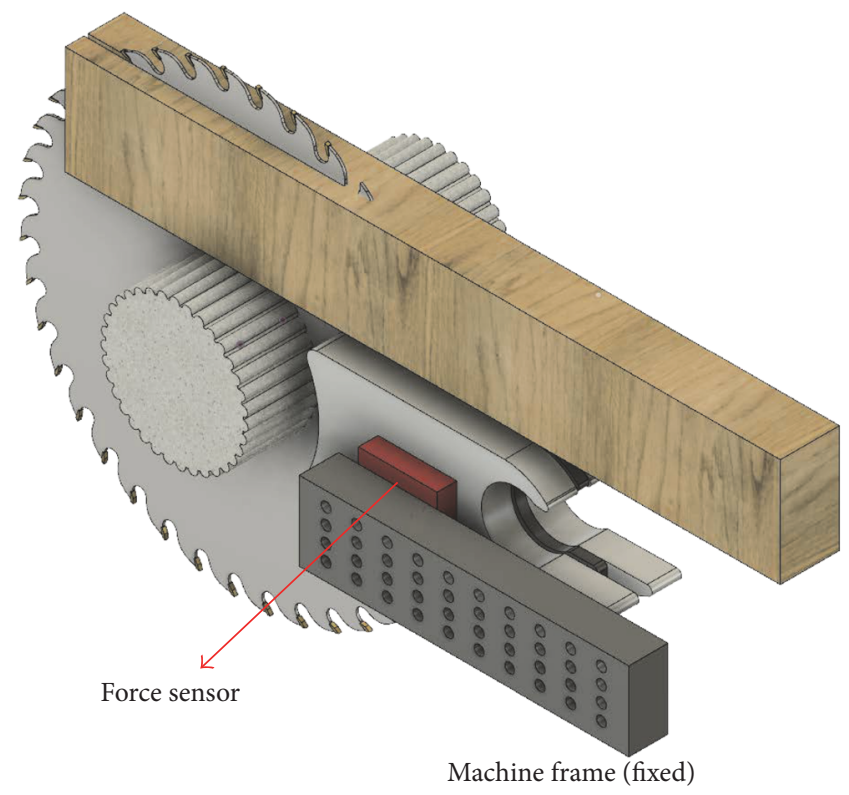

FIGURE 7: Schematic of installing the force sensor on the guided circular saw machine; sensor is placed between the machine frame and the guide arms.

computed. Table 4 summarized the average measured lateral force.

It should be mentioned that, theoretically, when a cut is straight and with no deviation, the lateral forces are zero. However, in practice due to many imperfections in the 

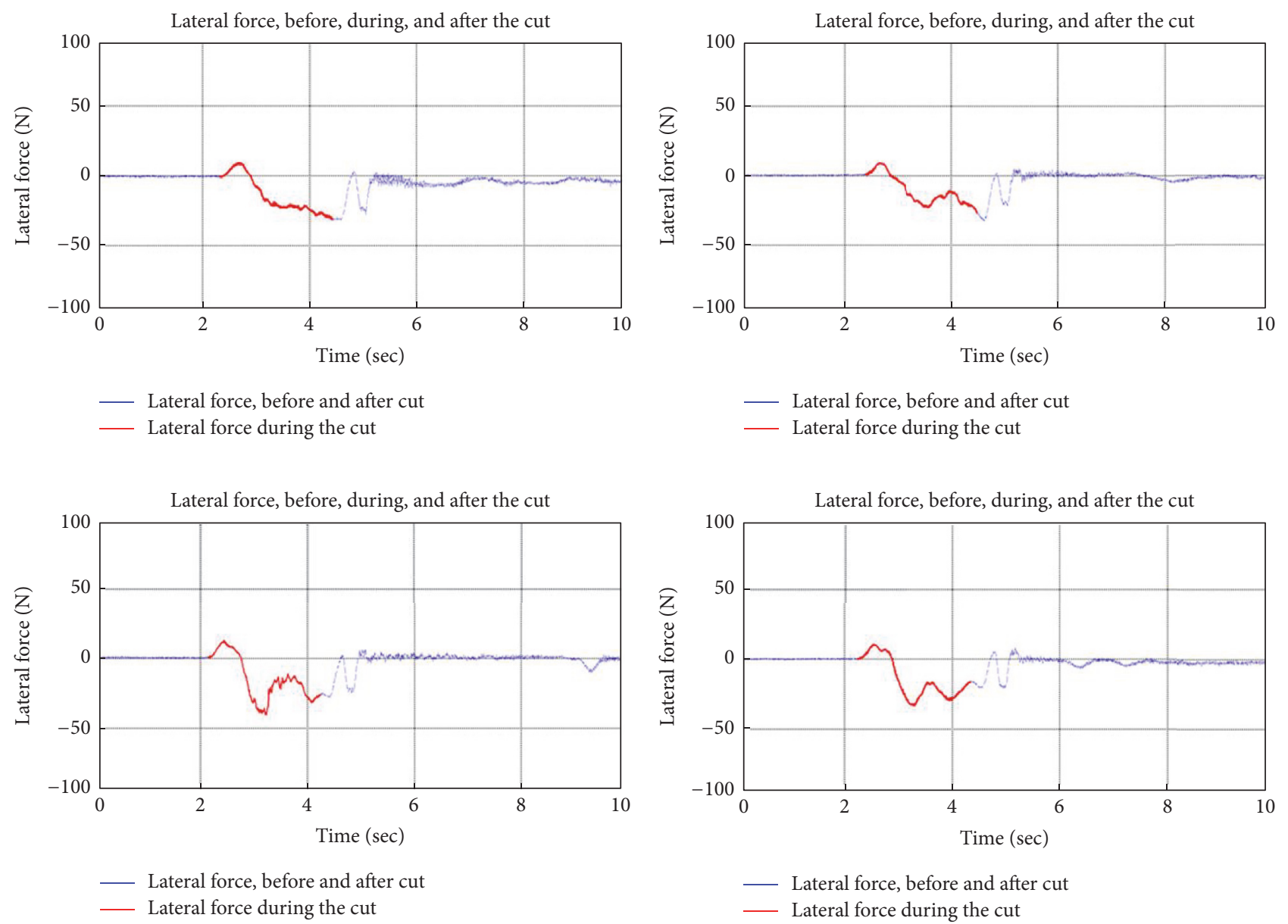

Figure 8: Measured lateral force, for 4 different cuts, $1800 \mathrm{rpm}$.

TABLE 4: Mean value of measured lateral force.

\begin{tabular}{lcccccc}
\hline Number & $\begin{array}{c}\text { Rotation speed } \\
(\mathrm{rpm})\end{array}$ & $\begin{array}{c}\text { Mean lateral } \\
\text { force in Cut 1 } \\
(\mathrm{N})\end{array}$ & $\begin{array}{c}\text { Mean lateral } \\
\text { force in Cut 2 } \\
(\mathrm{N})\end{array}$ & $\begin{array}{c}\text { Mean lateral } \\
\text { force in Cut 3 } \\
(\mathrm{N})\end{array}$ & $\begin{array}{c}\text { Mean lateral } \\
\text { force in Cut 4 } \\
(\mathrm{N})\end{array}$ & $\begin{array}{c}\text { Average lateral } \\
\text { force }(\mathrm{N})\end{array}$ \\
\hline$(1)$ & 1800 & 14 & 10 & 14 & 13 & 12.5 \\
$(2)$ & 2800 & 19 & 20 & 17 & 18 & 18.5 \\
\hline
\end{tabular}

system, such as guide and arbor misalignments, blade lack of flatness, and teeth misalignment, the lateral forces are not zero. For instance, in these cutting tests, as you notice the lateral forces are small but not zero.

Experimental tests facilities have been developed at FPInnovations (Canada's national forest products research institute) (Lumber Manufacturing Pilot Plant, Vancouver, Canada) which enables the measurement of the variation of natural frequencies of the blade with its rotation speed. A schematic of the experimental setup is presented in Figure 10. To measure the blade deflection, a noncontact inductance probe is used. Electromagnetic excitation is used to provide white noise excitation over a certain frequency range. To investigate the dynamic characteristics of rotating saws when subjected to the effect of a stationary lateral constant force, an air jet is used in order to apply lateral load to the saw. The magnitude of the air jet force is kept at a constant value by keeping a constant air pressure. Saw vibration results are obtained by measuring the deflection response of the blades at the locations of the displacement probe as the speed is ramped up from $0 \mathrm{rpm}$ to $4,000 \mathrm{rpm}$ at a constant rate over $1600 \mathrm{~s}$.

To verify the dynamic behaviour of the model during cutting, experimental cutting tests are conducted at saw speed of $1800 \mathrm{rpm}$ and $2800 \mathrm{rpm}$ and a constant feed speed of $400 \mathrm{fpm}$ and $600 \mathrm{fpm}$ for each saw speed, respectively. The deflection of the blade is measured by the displacement probe which was placed above the cut (Figure 11), before, during, 


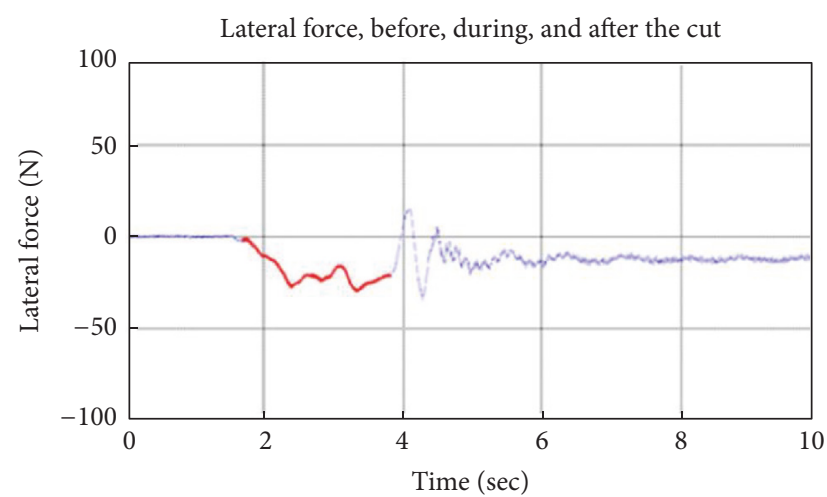

— Lateral force, before and after cut

_ Lateral force during the cut

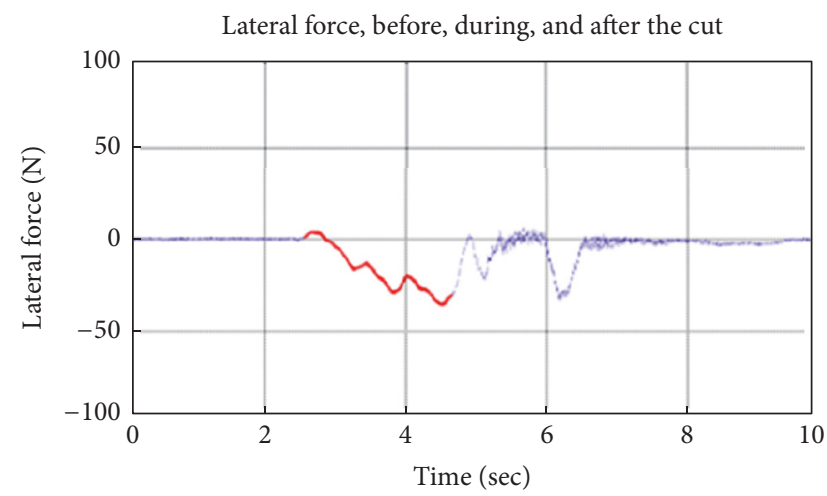

_ Lateral force, before and after cut

— Lateral force during the cut

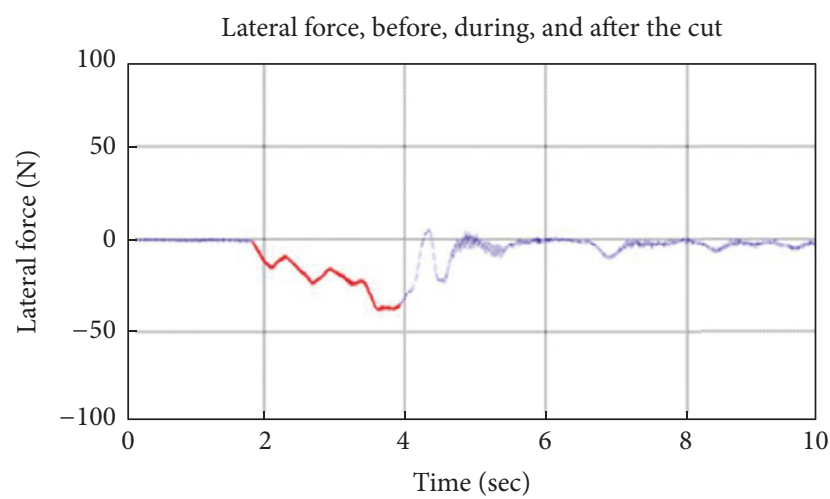

- Lateral force, before and after cut

_ Lateral force during the cut

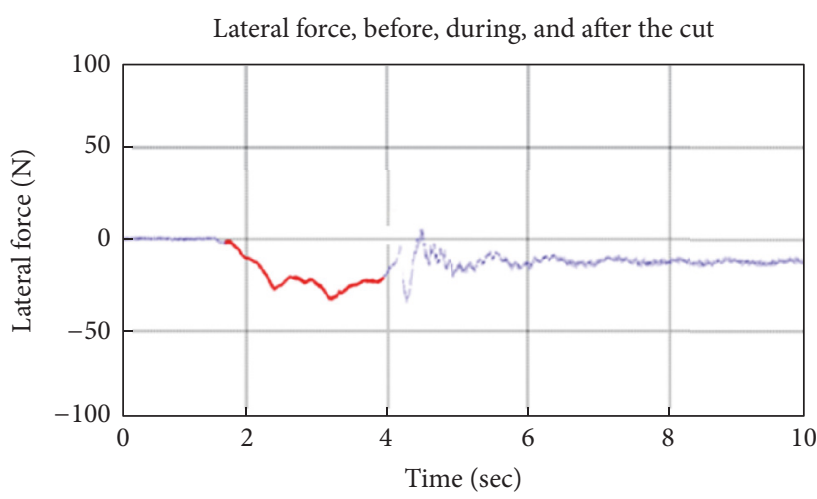

— Lateral force, before and after cut

L Lateral force during the cut

FiguRE 9: Measured lateral force, for 4 different cuts, $2800 \mathrm{rpm}$.

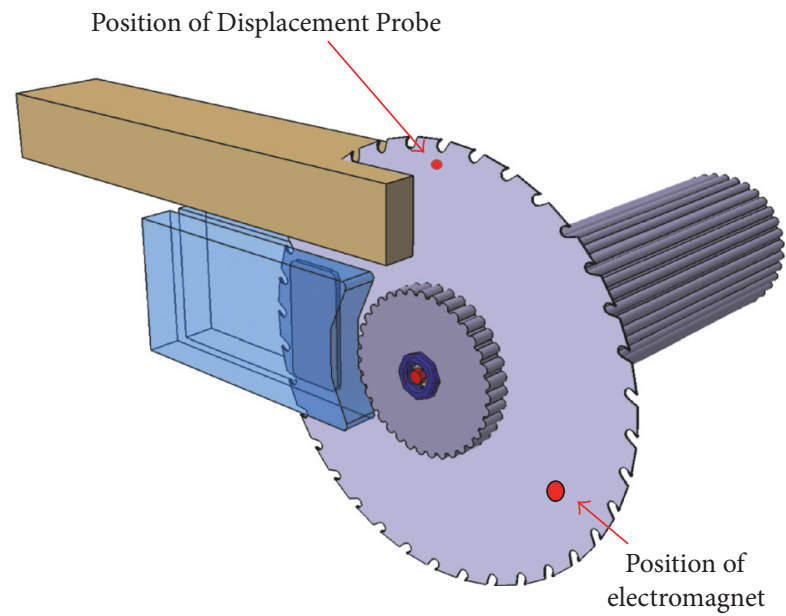

FIGURE 10: Schematic of the experimental setup.

and after the cut. For each test the cut profile is also measured by scanning the surface of the cut board along its length (Figure 12).

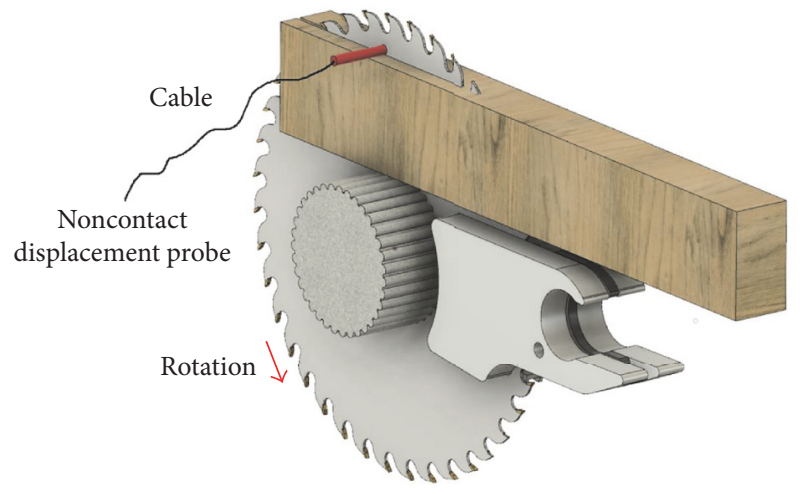

FIGURE 11: Noncontact displacement sensor, for measuring the saw deflection during a cut.

\section{Results}

The following sections discuss the idling and cutting experimental results for the saw and the correlation of these results with the results obtained by the computer model. 


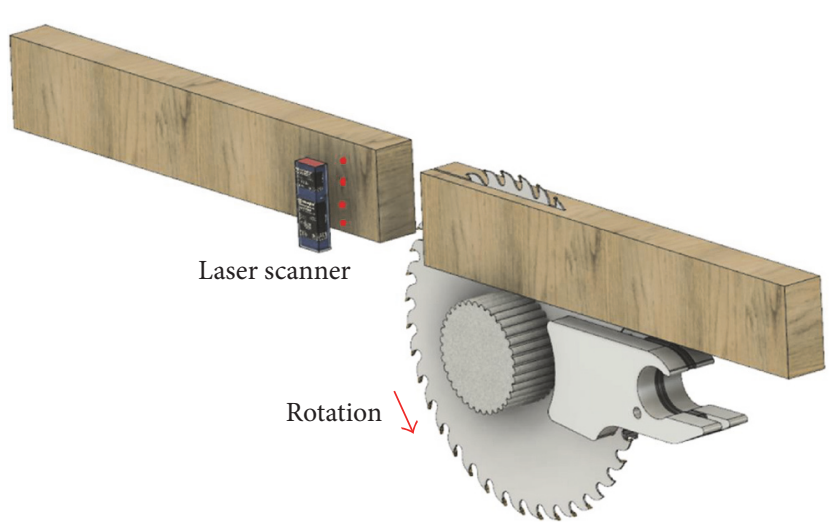

FIGURE 12: Schematic of scanning the surface of the workpiece after the cut by a laser scanner.

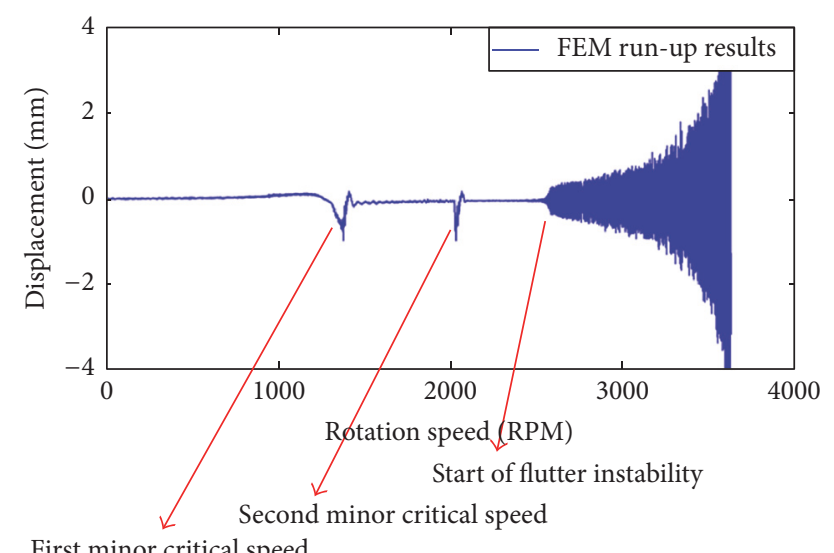

First minor critical speed

FIGURE 13: Deflection of the disk, during run-up, computed at outer radius, with angular position of $90^{\circ}$.

3.1. Idling Result. The computer model is run at a varying speed ramped up from 0 to $4000 \mathrm{rpm}$ at a constant rate over a period of 60 seconds, while being subjected to a constant small lateral force of $F_{l}=5 \mathrm{~N}$. Figure 13 shows the deflection of the disk at the outer radius at an angular position of $90^{\circ}$ (Figure 10). Computed results indicate that the disk experiences two critical speeds at about $1475 \mathrm{rpm}$ and $2100 \mathrm{rpm}$. Then a flutter type instability, characterized by increasing amplitude of vibration as the rotation speed increases [5], occurs at about $2500 \mathrm{rpm}$ (Figure 13).

Figure 14 shows the experimental measurement of the deflection of the blade during a run-up from 0 to $4000 \mathrm{rpm}$ (note that the tests had to be stopped at $3600 \mathrm{rpm}$ due to the very large vibrations of the blade). The experimental results show that blade suffers the first critical speed at about $1500 \mathrm{rpm}$, and a second critical speed occurs at about $2100 \mathrm{rpm}$. The blade experiences flutter vibrations at about $2500 \mathrm{rpm}$. These results show that the developed computer model can predict the critical speeds and flutter instability speeds of a guided spline circular saw with a very good accuracy.

Figure 14 shows that there is a sudden change in amplitude during flutter instability (at about $2700 \mathrm{rpm}$ ), and it also indicates that the blade slightly leans to one side during flutter instability. These phenomena have not been captured by the computer model. It is postulated that these phenomena might be due to slight imperfection in the system such as misalignment of the arbor or the guides, which is unavoidable in experimental tests. However, more research needs to be conducted to find the reasons for these sorts of behaviour at super flutter speeds which is beyond the scope of this paper. The paper by the authors in [3] provides more details on the dynamic behaviour of saws at super flutter speeds.

For further analysis of the results, an FFT of the time domain response is done for the experimental results. Figure 15 shows the distribution of excited frequencies of the blade as a function of rotation speed in the form of a color map plot. Frequency color maps of the power spectrum illustrate the variations of blade frequencies with rotation speed. It also illustrates the energy of the signal at each speed and frequency with a color spectrum. As the color map indicates, the frequencies (as measured by a space fixed observer) of each mode decrease as the rotation speed increases. The frequencies of the first and second mode reach zero at about $1500 \mathrm{rpm}$ and $2100 \mathrm{rpm}$ which are the first two critical speeds of the blade [2]. At $2500 \mathrm{rpm}$ the blade experiences flutter type instabilities.

Using the computer model, the dominant frequencies of the disk are computed at discrete speeds of $250 \mathrm{rpm}$ intervals. Table 5 shows the speeds and the frequencies at each speed. The table also shows the natural frequencies for when the disk is stationary. Notice that the natural frequencies of the stationary system should not be confused with the frequencies of the first 4 modes of stationary free disk [2], since now lateral constraints (guides) are added to the system and mass and stiffness of the system has changed. It is noticed in Table 5 that at some speeds the natural frequency of a mode becomes zero. These speeds correspond to the critical speeds of the system $[2,18]$.

To compare the frequency domain results, the computed dominant frequencies from the computer model are plotted on the same color map of experimental results (Figure 15). Comparing the computer results in the frequency domain with the experimental results indicates that there is a good agreement between the computer model and the experimental idling results up to the speed of flutter instability (about $2500 \mathrm{rpm}$ ). After the start of the flutter, the experimental results illustrate that there are several other excited frequencies which are not produced by the computer model. For example, after flutter instability speed, there are several lockin frequency paths which the computer model was not able to produce. It is postulated that behaviour at super flutter speeds is due to large deflection of the blade and the subsequent nonlinear behaviour of the system, which cannot be captured by a linear model [1] such as the developed computer model here. More research needs to be conducted on the dynamic behaviour, especially the nonlinear behaviour of the guided spline disks at speeds beyond the flutter instability speeds which is beyond the discussion of this paper.

It is also noticed from Figure 15 that there are some frequency paths that start from zero and increase linearly with different slope as the rotation speed increases. These 


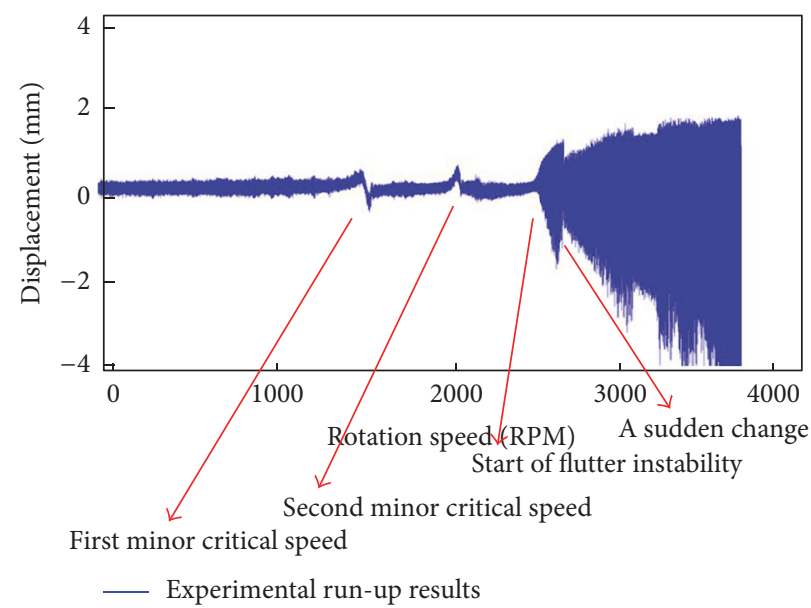

FIGURE 14: Deflection of the blade, during run-up, measured by probe $90^{\circ}$.

TABLE 5: Excited frequencies of the spline guided disk at different rotation speeds, FEM results.

\begin{tabular}{|c|c|c|c|c|c|}
\hline Number & Rotation speed (RPM) & Frequency $1(\mathrm{~Hz})$ & Frequency $2(\mathrm{~Hz})$ & Frequency $3(\mathrm{~Hz})$ & Frequency $4(\mathrm{~Hz})$ \\
\hline$(1)$ & 0 (Statinary) & 9 & 10.5 & 26 & 43 \\
\hline (2) & 250 & 5.5 & 14 & 26.5 & 42.5 \\
\hline (3) & 500 & 4.5 & 15.5 & 28 & 41 \\
\hline (4) & 750 & 4 & 14 & 27 & 42 \\
\hline (5) & 1000 & 3 & 13.5 & 26.5 & 40.5 \\
\hline (6) & 1250 & 1 & 9 & 22 & 38 \\
\hline (7) & 1500 & 0 & 7.5 & 20.5 & 32 \\
\hline (8) & 1750 & 0 & 4 & 13.5 & 26 \\
\hline (9) & 2000 & 4 & 0 & 9 & 20 \\
\hline$(10)$ & 2250 & 8.5 & 3 & 3 & 15 \\
\hline (11) & 2500 & 9 & 5 & 0 & 5 \\
\hline (12) & 2750 & 9 & 4.5 & 0 & 4.5 \\
\hline (13) & 3000 & 9 & 4 & 0 & 1 \\
\hline (14) & 3250 & 9 & 4 & 0 & 0 \\
\hline (15) & 3500 & 9 & 4 & 0 & 0 \\
\hline
\end{tabular}

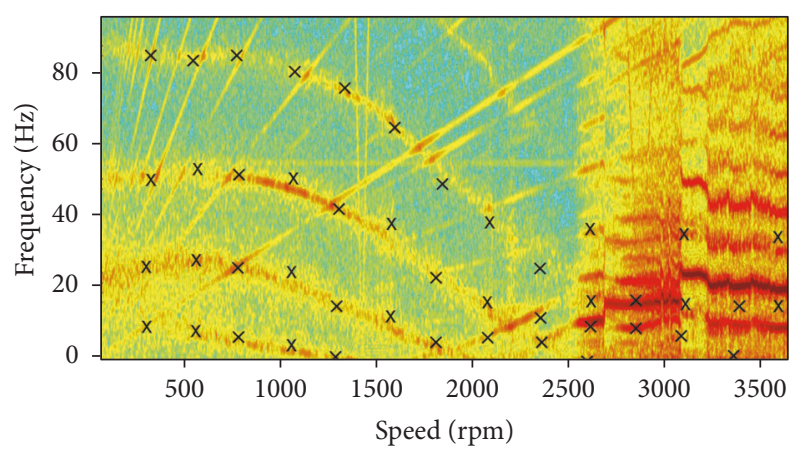

FIGURE 15: Variation of excited frequencies of the blade as a function of rotation speed. Color map experimental results; $\times$ represents the model results.

frequency paths were not captured by the computer model. This is due to the fact that there are imperfections in the balance and interaction of the components of most practical rotating machines. As a result of these imperfections, rotating parts of machines generate vibration. Common sources of vibrations arise due to mechanical looseness, mass unbalance, eccentricity, misalignments, bent shaft, pulleys, external forces, and rubbing. These faults usually yield vibration levels with harmonic levels of $1 X, 2 X, 3 X, \ldots$ and subharmonic levels of vibration such as $X / 2, X / 3, \ldots$ of rotation speed which can be seen in the color map. If the frequency of excitation generated by a rotating part coincides with the natural frequencies of the rotating blade, resonant interaction can be expected [2].

3.2. Cutting Results. The components of cutting force, calculated in Section 2, are applied at each tooth in the cutting zone. In this work, for $200 \mathrm{~mm}$ depth of cut, 4 teeth are in the cut at any time. The vibration of the disk is computed before, during, and after applying the forces. Duration of applying 


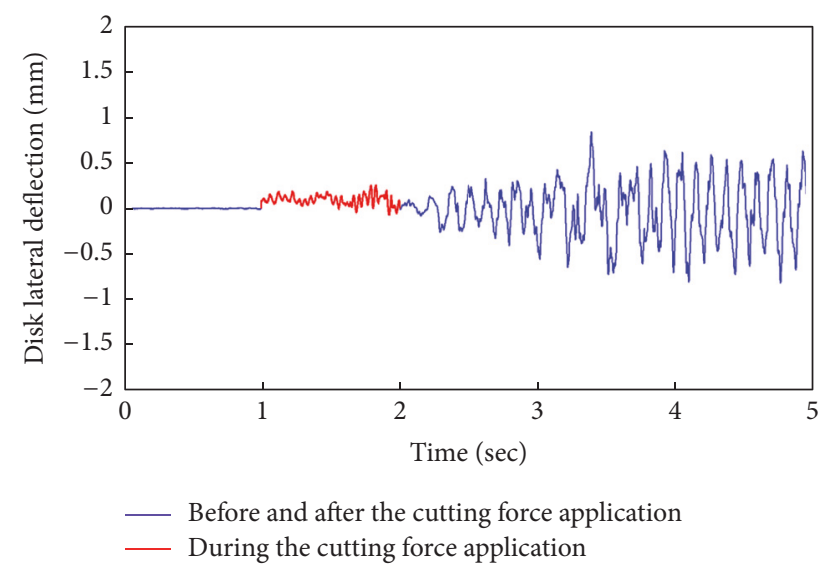

FIGURE 16: FEM results, disk lateral deflection at position of outer radius, angle $90^{\circ}$, subjected to cutting forces, at rotation speed $1800 \mathrm{rpm}$.

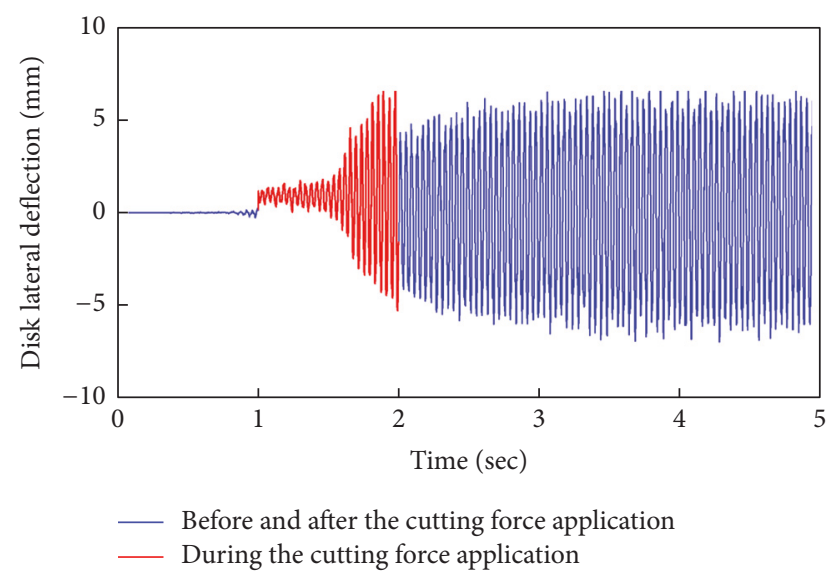

FIGURE 17: FEM results, disk lateral deflection at position of outer radius, angle $90^{\circ}$, subjected to cutting forces, at rotation speed $2800 \mathrm{rpm}$.

forces is set to match the feed speeds chosen at each saw speed (details in Section 2).

Figures 16 and 17 show the vibrations of the disk, before, during, and after applying the loads, computed by the computer model. Figure 16 indicates that, at saw speed of $1800 \mathrm{rpm}$, the disk is stable after application of the forces. Figure 17 shows at $2800 \mathrm{rpm}$, the amplitude of disk vibrations is significantly larger than the results at $1800 \mathrm{rpm}$. At $2800 \mathrm{rpm}$, which is a super flutter speed, application of the forces makes the disk unstable. The amplitude of vibration increases rapidly when the disk is subjected to the cutting forces. The dominant frequency of the vibration is about $24 \mathrm{~Hz}$. After releasing of the forces, the vibration of the disk does not damp out. It should be noted that the analysis of the computer model contains no damping. As it is expected, the spline disk, subjected to the edge loads, is stable at speeds below the flutter speed and unstable after flutter speed [5].

As explained in previous section, during each experimental cutting test, the deflection of the blade is measured by the displacement probe. Figures 18 and 19 show the experimental cutting results at $1800 \mathrm{rpm}$ and $2800 \mathrm{rpm}$, respectively. Each graph indicates the deflection of the blade, measured by the probe $90^{\circ}$, before, during, and after the cut. Each set of tests (1800 rpm and $2800 \mathrm{rpm}$ ) was repeated 4 times. It should be noted that the wood cutting results for the same conditions are not exactly the same. This is due to the fact that wood is not a homogeneous material. The results indicate that the blade suffers large deflection after it exits the cut; then it settles down after a few seconds. The result from $1800 \mathrm{rpm}$ which is below the blade flutter instability speed shows that the cutting deviation is small, compared with the results from conducting cuts at $2800 \mathrm{rpm}$ which is above the instability speed of the blades.

Although the deflection of the disk, computed by the model, and the experimental results do not match, the stability behaviour of the system predicted by the computer model and the practical results are in accord. At $2800 \mathrm{rpm}$, the computer results show that the disk vibrates with frequency of about $24 \mathrm{~Hz}$ which is close to the dominant natural frequency of the system during idling. But in experimental tests at $2800 \mathrm{rpm}$, the deflection of the blade is at low frequency vibration (less than $5 \mathrm{~Hz}$ ). In other words, cutting at the flutter speed results is a low frequency vibration and there is no correlation between the dominant frequency of it and the idling excited frequencies. It is postulated that there might be other factors that have significant effect on the characteristics of guided saw during a cut. These factors may be any or a combination of body of the blade and wood interaction, varying cutting forces, variation of lateral force as a function of blade lateral speed, friction between spline arbor and blade, wood damping, heating of the blade, aerodynamic forces, hunting phenomenon of the blade, and varying spline interaction of saw and arbor due to friction (blade body and wood). Studies of these factors are important to understand the cutting characteristics of guided spline saws which need to be undertaken.

\section{Conclusion}

A finite element model of guided spline circular saws is developed to simulate the dynamic characteristics of the system in idling and cutting modes. Experimental verification of the computer model shows that the model can predict some of the stability characteristics of the system in an idling situation, such as critical speeds, flutter instability speed, and the dominant excited frequencies of the blade before flutter instability. Although the deflection of the disk, computed by the model, and experimental results do not match, the stability behaviour of the system predicted by the computer model and the practical results are in accord. There are many factors that might have significant effect on the dynamic behaviour of system during cutting which need to be undertaken for a realistic analysis of the system. Such factors include (i) body of the blade and wood interaction, (ii) friction between spline arbor and blade, (iii) effect of damping from wood, (iv) the effect of temperature on the saw during cutting, and ( $\mathrm{v}$ ) varying spline interaction of saw and arbor due to friction (blade body and wood). 

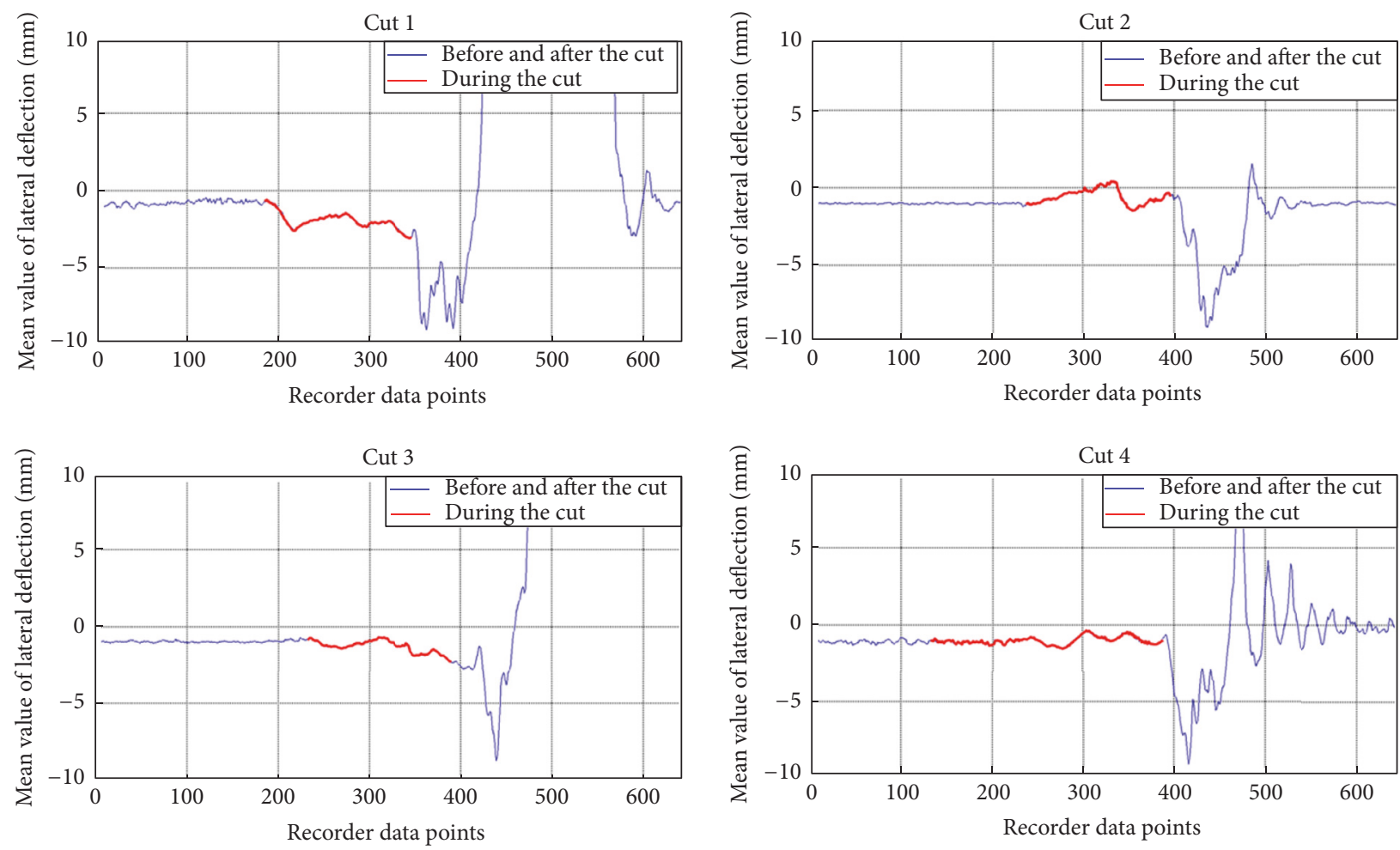

FIGURE 18: Experimental cutting results, cut at $1800 \mathrm{rpm}$.
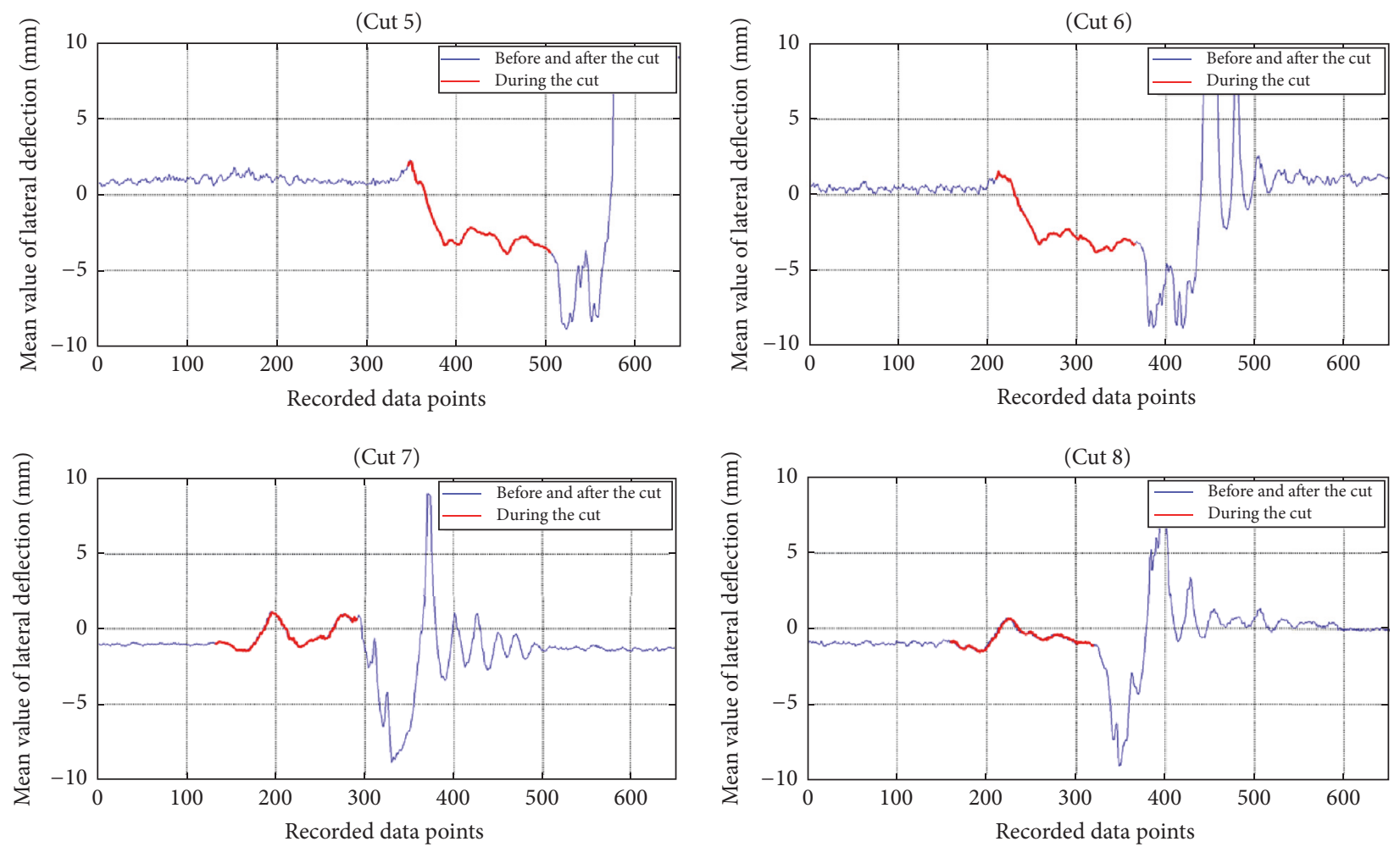

FIGURE 19: Experimental cutting results, cut at $2800 \mathrm{rpm}$. 


\section{Conflicts of Interest}

The authors declare that they have no conflicts of interest.

\section{References}

[1] A. Mohammadpanah, Flutter instability speed of guided spline disks, with applications to sawing [Ph.D. thesis], University of British Columbia, Canada, 2015.

[2] A. Mohammadpanah, Idling and Cutting Vibration Characteristics of Guided Circular saws, Thesis Submitted in Partial Fulfillment for the Degree of M.A.Sc, University of British Columbia, Canada, 2012.

[3] A. Mohammadpanah and S. G. Hutton, "Flutter instability speeds of guided splined disks: An experimental and analytical investigation," Shock and Vibration, vol. 2015, Article ID 942141, 2015.

[4] A. Mohammadpanah and S. G. Hutton, "Maximum operation speed of splined saws," Wood Material Science and Engineering, vol. 11, no. 3, pp. 142-146, 2016.

[5] A. Mohammadpanah and S. G. Hutton, "Dynamics behavior of a guided spline spinning disk, subjected to conservative inplane edge loads, analytical and experimental investigation," ASME, Journal of Vibration and Acoustics, vol. 138, no. 4, Article ID 041005, 2016.

[6] R. M. H. Khorasany, A. M. Panah, and S. G. Hutton, "Vibration characteristics of guided circular saws: experimental and numerical analyses," Transactions of the ASME-Journal of Vibration and Acoustics, vol. 134, no. 6, Article ID 061004, 2012.

[7] R. M. H. Khorasany and S. G. Hutton, "An analytical study on the effect of rigid body translational degree of freedom on the vibration characteristics of elastically constrained rotating disks," International Journal of Mechanical Sciences, vol. 52, no. 9, pp. 1186-1192, 2010.

[8] J.-S. Chen and B. D. Bogy, "Natural frequencies and stability of a flexible spinning disk-stationary load system with rigid-body tilting," Journal of Applied Mechanics, vol. 60, no. 2, pp. 470-477, 1993.

[9] J. S. Chen and C. C. Wong, "Modal interaction in a spinning disk on a floating central collar and restrained by multiple springs," The Journal of the Chinese Society of Mechanical Engineers, vol. 17, no. 3, pp. 251-259, 1996.

[10] G. S. Schajer and S. A. Wang, "Effect of work piece interaction on circular saw cutting satiability," European Journal of Wood and Wood Products, vol. 60, no. 1, pp. 48-54, 2002.

[11] G. S. Schajer, "Guided saw hunting," Forest Products Journal, vol. 38, no. 4, pp. 47-50, 1984.

[12] ANSYS Academic Research, Release 13.0.

[13] MSC ADAMS, ADMAS VIEW, Release 2012.

[14] N. Kikuchi and J. T. Oden, Contact Problems in Elasticity: A Study of Variational Inequalities and Finite Element Methods, vol. 8 of SIAM Studies in Applied Mathematics, Society for Industrial and Applied Mathematics (SIAM), Philadelphia, PA, 1988.

[15] Oi. Kazimierz and T. Ochrymiuk, "A newly-developed model for predicting cutting power during wood sawing with circular saw blades. Maderas," Ciencia y tecnología, 2017.

[16] A. Kaczmarek, O. Kazimierz, and J. Lubomir, "Comparison of natural frequencies of a circular sa w blade obtained empirically and with FEM," Annals of Warsaw University of Life Sciences Forestry and Wood Technology, pp. 46-50, 2016.
[17] D. G. Cuppett, "Power consumption and lumber yields for reduced-kerf circular saws cutting hardwoods," Tech. Rep. Call Number 8-01 (748) N814 Res. Pap. NE-505, FPInnovations Vancouver Library (University of British Columbia Campus), 1982.

[18] A. Mohammadpanah, S. G. Hutton, and R. M. H. Khorasany, "Critical speeds of guided circular saws - a sensitivity analysis to design variables," in Proceedings of the 23rd Canadian Congress of Applied Mechanics, pp. 344-347, University of British Columbia, Columbia, Canada, June 2011. 


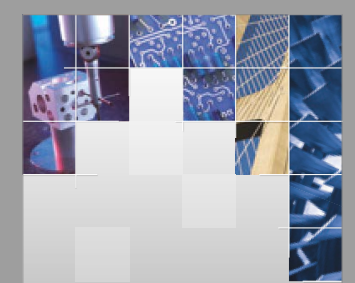

\section{Enfincering}
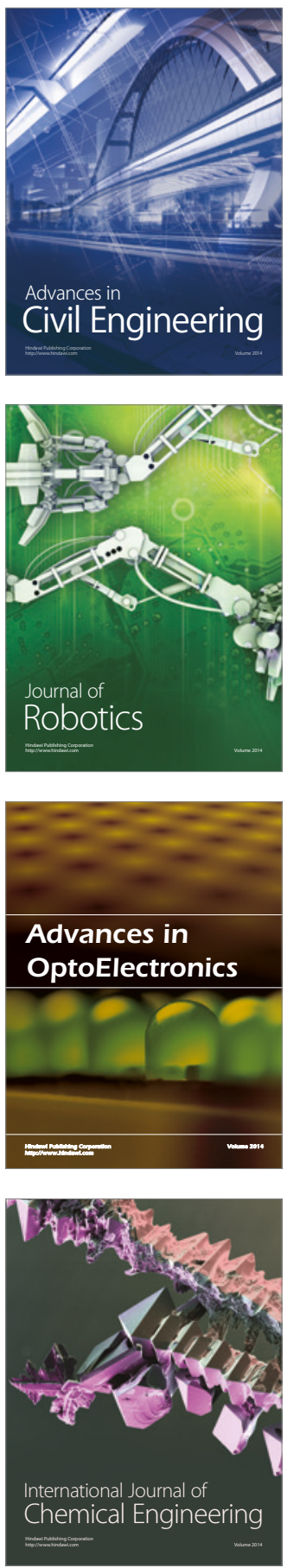

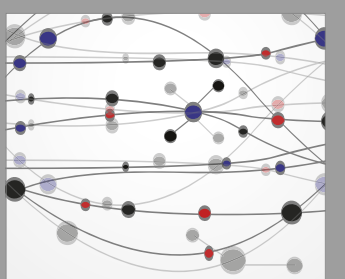

The Scientific World Journal

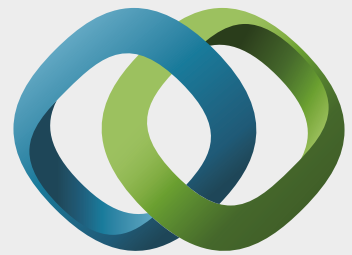

\section{Hindawi}

Submit your manuscripts at

https://www.hindawi.com
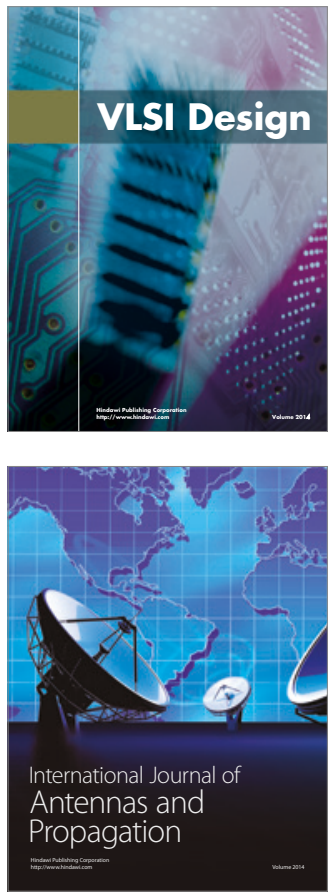

\section{Rotating}

Machinery
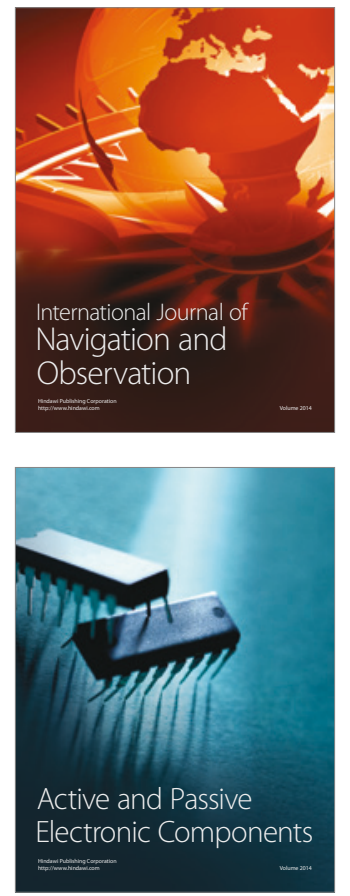
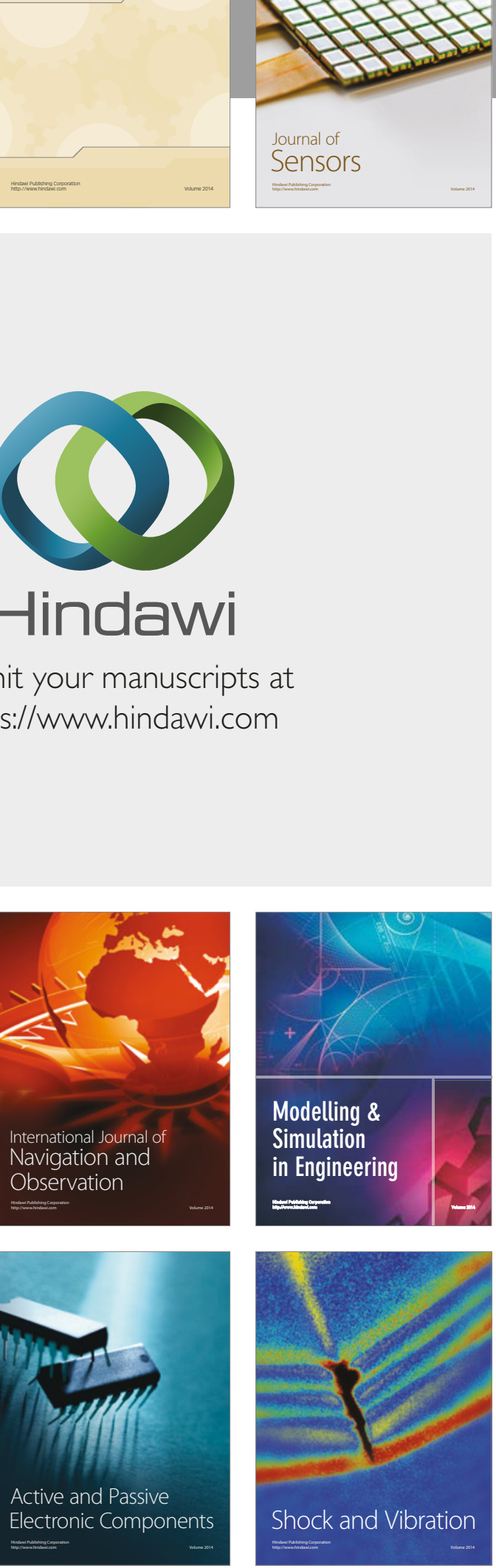
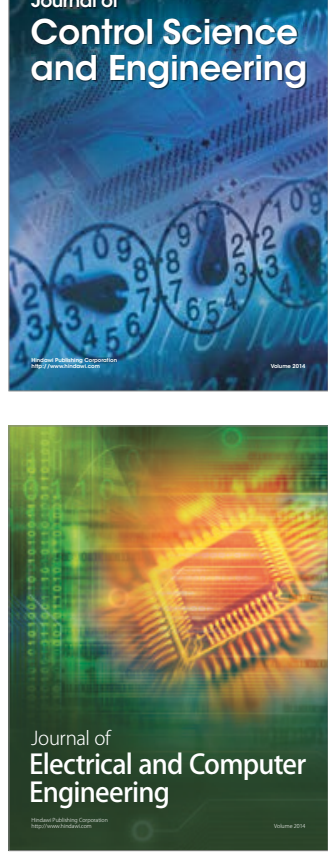

Distributed

Journal of

Control Science

and Engineering
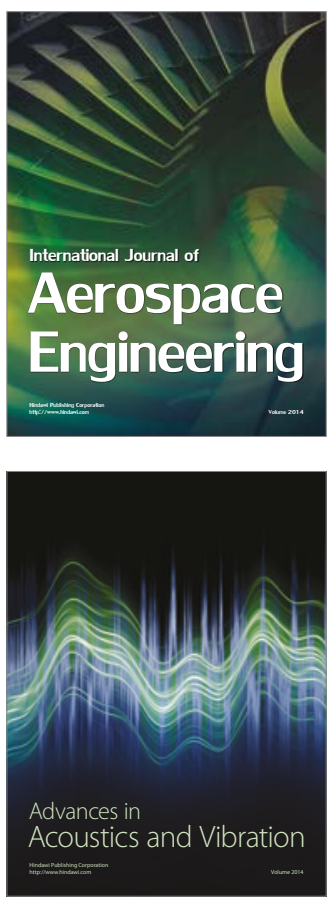

Sensor Networks 